\title{
Metodologia para avaliação do desgaste por abrasão de bocais de aspersores rotativos ${ }^{1}$
}

\author{
Delvio Sandri ${ }^{2}$ Edson E. Matsura ${ }^{3} \&$ Roberto Testezlaf ${ }^{4}$
}

\begin{abstract}
1 Parte da Dissertação de Mestrado do primeiro autor. Pesquisa financiada pela FAPESP (Processo 97/032236)
2 FEAGRI/UNICAMP. Cidade Universitária "Zeferino Vaz", CP 6011, CEP 13081-970, Campinas, SP. Fone: (19) 3788-1001, Fax: (19) 3788-1010. E-mail: sandri@agr.unicamp.br (Foto)

3 DAGSOL/FEAGRI/UNICAMP. Fone: (19) 3788-1023. E-mail: matsura@agr.unicamp.br

4 DAGSOL/FEAGRI/UNICAMP. Fone: (19) 3788-1024. E-mail: bob@agr.unicamp.br
\end{abstract}

Protocolo 167 - 28/11/2001 - Aprovado em 19/2/2003

\begin{abstract}
Resumo: As técnicas de manejo de irrigação, as condições hidráulicas e a durabilidade dos equipamentos diante das diferentes condições de uso, são fatores importantes a serem considerados no desempenho de sistemas de irrigação e que devem ser avaliados permanentemente. Diante disto, este trabalho teve como objetivo analisar uma metodologia de quantificação de desgaste de bocais de aspersores rotativos, utilizando-se uma mistura sólido-líquida (areia-água) avaliando-se a variação da vazão, da massa do bocal, do coeficiente de descarga, das dimensões dos bocais e comportamento do módulo hidráulico. Foram ensaiados aspersores com bocais de latão, plástico e bronze, submetidos às concentrações de sólidos de $140 \mathrm{mg} \mathrm{L}^{-1} \pm 10 \%\left(\mathrm{C}_{1}\right)$ e $230 \mathrm{mg} \mathrm{L}^{-1} \pm 10 \%$ $\left(\mathrm{C}_{2}\right.$ ) operando a uma pressão de serviço de $300 \mathrm{kPa}$, durante o tempo total de ensaio de $2100 \mathrm{~h}$, com intervalo de leitura a cada $150 \mathrm{~h}$. O módulo hidráulico mostrou ser capaz de simular o desgaste de bocais de aspersores para ambas as concentrações de sólidos, apesar de se ter verificado um aquecimento da mistura sólido-líquida. A medição dos diâmetros dos bocais, através da confecção de moldes, mostrou-se eficiente e com precisão adequada aos objetivos do trabalho, com resultados menos consistentes para o bocal de plástico. Os aumentos de vazão em relação aos valores iniciais foram de 2,97, 1,98 e 0,96\% para os bocais de latão, plástico e bronze, respectivamente, sendo iguais para as duas concentrações de sólido.
\end{abstract}

Palavras-chave: material de fabricação, durabilidade, metodologia de desgaste de bocais

\section{Methodology for evaporation of abrasion wearing of sprinkler nozzles}

\begin{abstract}
The irrigation management techniques, the hydraulic conditions and durability of the equipment under different operation conditions are important factors to be considered in irrigation systems and must be evaluated permanently. The main scope of this work was to analyze a methodology to quantify the abrasive effect of solid-liquid mixtures on rotary sprinklers nozzles and evaluating the effect of the variation in discharge, nozzle mass, discharge coefficient, dimensions of sprinkler nozzles made of brass, plastic and bronze and hydraulic system on performance. Two water - sand solutions having solid concentrations of $140 \mathrm{mg} \mathrm{L}^{-1} \pm 10 \%\left(\mathrm{C}_{1}\right)$ and $230 \mathrm{mg} \mathrm{L}^{-1} \pm 10 \%\left(\mathrm{C}_{2}\right)$. The operation pressure was $300 \mathrm{kPa}$ with a test duration of $2100 \mathrm{~h}$ and readings interval of $150 \mathrm{~h}$. The hydraulic module showed to be capable to simulate the wear of sprinkler nozzles for both concentrations of solids, although heating of the solid-liquid mixture was found to increase. The use of molds to measure the nozzle diameter, showed efficient and adequate precision the objective of this work, with less consistent results for the plastic for nozzles. The sprinkler discharge increased $2.97,1.98$ and $0.96 \%$ for the brass, plastic and bronze nozzles, respectively, for both solid concentrations.
\end{abstract}

Key words: manufacturing materials, durability, methodology of the nozzle wear

\section{INTRODUÇÃO}

Em fontes de água utilizadas na irrigação geralmente é encontrada certa quantidade de sólidos suspensos, que podem causar algum tipo de dano ao sistema de irrigação. Aliado ao fato de que na irrigação por aspersão e microaspersão normalmente nem sempre são utilizados sistemas de filtragem para retirada dessas partículas sólidas, este trabalho buscou simular uma situação real, em que se considerou o efeito da concentração média de sólidos, como normalmente encontrada nas águas dos rios da região de Campinas, SP, através de uma mistura sólido-líquida, sobre bocais de aspersores rotativos.

A presença de partículas sólidas na água de irrigação pode provocar aumento no processo de desgaste dos bocais, pelo 
atrito dessas com as suas paredes internas. A conseqüência deste fato pode levar a um desequilíbrio hidráulico do sistema e comprometer a uniformidade de distribuição de água, ou mesmo exceder a capacidade dos filtros, bombas e sistema de tubulação. O desgaste dos bocais dos aspersores pode aumentar com o tempo de uso e com a concentração e característica dos sólidos presentes na água de irrigação. $\mathrm{O}$ resultado pode ser uma aplicação maior de água, provocando desperdícios por percolação profunda e escoamento superficial, além de danos ao solo (Karmeli et al., 1982; Boman \& Parsons, 1993).

Os principais fatores que podem influenciar no desgaste abrasivo de bocais, são: densidade, dureza, tamanho e forma das partículas sólidas, concentração e viscosidade da mistura, composição, forma e dureza dos materiais de fabricação dos equipamentos, pressão de funcionamento, características de escoamento e vazão, velocidade da mistura e ângulo de impacto das partículas sólidas (Truscott, 1972; Karmeli et al., 1982; Boman \& Parsons, 1993 e Nanduri et. al., 2002).

Um modelo para a manutenção e substituição periódica de bocais de aspersores foi desenvolvido por Karmeli et al. (1982) que consideraram o aumento do custo da água comparada ao custo de substituição dos bocais, em função do desgaste e da variação de pressão nos bocais. Esses autores consideraram, ainda, que o diâmetro do bocal aumenta de forma constante com o tempo de ensaio, sendo esta uma medida relativa ao aumento do diâmetro do bocal, por unidade de tempo (normalmente h). Peri \& Karmelli, citados por Karmelli et al. (1982) obtiveram valores de $0,2 \times 10^{-5} \mathrm{~h}^{-1}(2 \%$ de aumento em $1000 \mathrm{~h}$ de ensaio) a $5 \times 10^{-5} \mathrm{~h}^{-1}(5 \% \mathrm{em} 1000 \mathrm{~h}$ de ensaio) porém, quando aumentaram a quantidade de areia na água, o desgaste aumentou para $2 \times 10^{-4} \mathrm{~h}^{-1}$ ( $2 \%$ do aumento do diâmetro em $100 \mathrm{~h}$ de ensaio).

O momento correto para a substituição dos bocais depende do custo dos bocais novos em relação ao custo da água, da vazão dos bocais, da vida útil do aspersor e da taxa de desgaste dos bocais por unidade de tempo, que é função principalmente da pressão de operação, da qualidade da água (concentração de sólidos) e da qualidade dos bocais. Segundo Karmelli et al. (1982) para alta pressão de operação e baixa qualidade da água (muitos sólidos suspensos) o desgaste pode ser alto ( $2 \times 10^{-4}$ $\mathrm{h}^{-1}$ ou $2 \%$ em $100 \mathrm{~h}$ ) e, para baixa pressão e boa qualidade da água, pode ser baixo $\left(2 \times 10^{-6} \mathrm{~h}^{-1}\right.$ ou $\left.0,02 \% \mathrm{em} 100 \mathrm{~h}\right)$. Esses autores, usando bocais de menor qualidade (material de menor resistência ao desgaste) mostraram a necessidade dos mesmos serem substituídos de 7 a 15 vezes durante a vida útil do aspersor, ou aproximadamente uma vez a cada ano. Em bocais de alta qualidade (resistente ao desgaste abrasivo) o desgaste foi reduzido e o mesmo precisou ser substituído uma única vez, ou duas, durante a vida do aspersor.

Bomam \& Parsons (1993) realizando trabalho com o objetivo de determinar o desgaste em emissores ao longo de seu uso e o aumento de vazão, observaram que, para $2000 \mathrm{~h}$ de operação a $207 \mathrm{kPa}$, os emissores estudados apresentaram aumento de vazão que variou entre 7,5\% e $11 \%$. Verificaram, ainda, que com a mudança de pressão de 138 para $207 \mathrm{kPa}$, a velocidade da água aumentou levando, conseqüentemente, a um desgaste maior dos bocais.
Nanduri et al. (2002) conduziram estudo para avaliarem o desgaste acelerado de bocais através de um jato abrasivo de água (AWJ), que é um sistema que utiliza altas pressões e orifícios de pequeno diâmetro, avaliando o efeito do comprimento, ângulo interno e diâmetro no desgaste abrasivo dos bocais. Assim, foi construído e utilizado um bocal para cada situação, com comprimento variando de 32,5-101,6 mm, ângulo interno de $10-180^{\circ}$, diâmetro do bocal de $0,79-1,63 \mathrm{~mm}$ e pressões de 172-359 MPa. A variação do diâmetro interno dos bocais foi medida por meio da utilização de uma resina de silicone, através da confecção de moldes e os resultados expressos em $\% \mathrm{~min}^{-1} \mathrm{e}$ a perda de massa dos bocais em $\mathrm{g} \mathrm{min}{ }^{-1}$. Constataram que a perda de peso diminui com o aumento do comprimento do bocal e que ocorrem diferenças no desgaste do bocal para os diferentes ângulos interno dos bocais, aumentando conforme se aumenta o ângulo. Esses autores consideraram que o desgaste interno do bocal ocorre de forma não linear ao longo do comprimento, aumentando mais, quanto maior for o diâmetro do bocal.

Este trabalho teve como objetivo analisar uma metodologia de quantificação do desgaste de bocais, causado pela mistura sólido-líquido (areia-água) em bocais de aspersores rotativos.

\section{MATERIAL E MÉTODOS}

Os ensaios foram realizados no Laboratório de Hidráulica e Irrigação da Faculdade de Engenharia Agrícola da Universidade Estadual de Campinas, FEAGRI/UNICAMP, seguindo-se a Norma ISO 7749-1 (ISO, 1995) (E) recomendada para testes de durabilidade de aspersores com água limpa, na qual o aspersor deve ser testado pelo período de $2000 \mathrm{~h}$. Buscando-se atender a este tempo mínimo e se definindo um intervalo de leitura entre cada medida de $150 \mathrm{~h}$, o ensaio foi conduzido pelo tempo total de $2100 \mathrm{~h}$. A adoção desta norma se deve à falta de uma norma específica que regulamente o tempo de teste de desgaste abrasivo de bocais de aspersores.

\section{Módulo Hidráulico}

Para efetivar a metodologia proposta, construíram-se dois módulos hidráulicos idênticos, um para cada concentração de sólido, tendo reservatórios em chapa de aço inox, com espessura de $3 \mathrm{~mm}$ e dimensões de $0,80 \mathrm{~m}$ de altura por $0,60 \mathrm{~m}$ de diâmetro, com fundo em formato cônico de $45^{\circ}$ (Figura 1).

Utilizaram-se duas motobombas, uma principal, para bombear a mistura para os aspersores, e uma misturadora, para provocar maior agitação e homogeneização da mistura dentro do reservatório. Um regulador de pressão de ação direta foi instalado antes de cada aspersor, permitindo melhor ajuste da pressão. Utilizaram-se cúpulas de plástico transparente, permitindo visualizar o funcionamento do aspersor e identificar possíveis problemas.

Durante os ensaios preliminares percebeu-se o aquecimento da água nos reservatórios, em virtude da rápida recirculação da mesma no circuito hidráulico. Para atenuar o problema, os dois módulos hidráulicos foram colocados dentro de um depósito com dimensões de $3,00 \mathrm{~m}$ de largura e $6,00 \mathrm{~m}$ comprimento, em que o nível da água no interior deste depósito era igual ao nível da mistura sólido-líquida, permitindo, assim, 


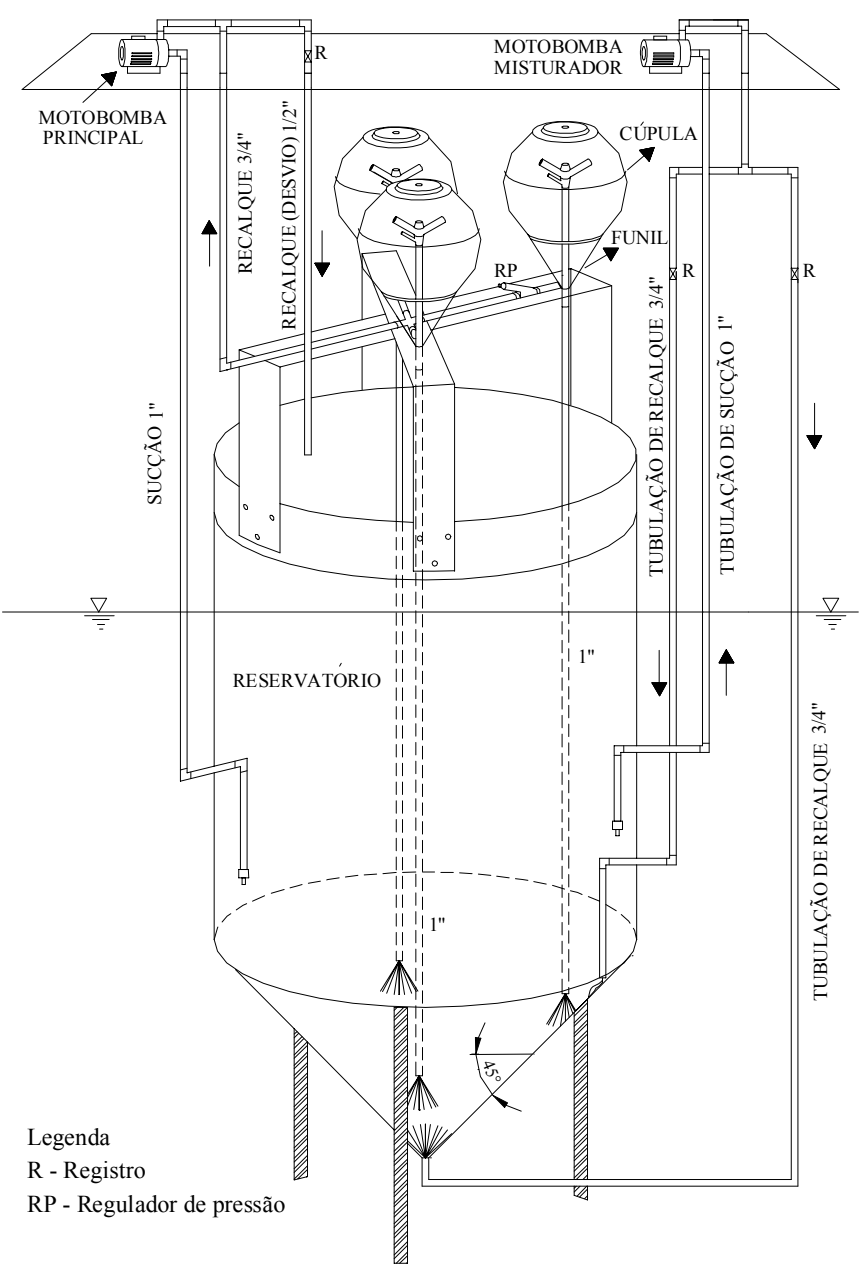

Figura 1. Esquema do circuito hidráulico utilizado nos ensaios

a troca de calor e mantendo a temperatura da mistura dentro de um valor aceitável $\left(<25^{\circ} \mathrm{C}\right)$ para ensaio de desgaste abrasivo.

\section{Metodologia de ensaio}

Para avaliação do módulo desenvolvido instalaram-se, em cada reservatório, três aspersores de diferentes materiais de fabricação, ou seja, latão, plástico e bronze, operando a uma pressão de serviço de $300 \mathrm{kPa}$, sendo simulada em cada reservatório, uma concentração de sólidos diferente, ou seja, $140 \mathrm{mg} \mathrm{L}^{-1} \pm 10 \%\left(\mathrm{C}_{1}\right)$ e $230 \mathrm{mg} \mathrm{L}^{-1} \pm 10 \%\left(\mathrm{C}_{2}\right)$ obtidos por uma mistura sólido-líquida (areia-água).

Os bocais de latão e plástico possuíam formato cônico convergente simples, com ângulos de $22^{\circ} 30$ e $13^{\circ} 40$, respectivamente, enquanto o bocal de bronze, de acordo com Li \& Kaw (1998) é classificado como retangular duplo, com convergência no centro e ângulo de $37^{\circ} 50^{\circ}$. As dimensões e o formato dos bocais utilizados podem ser vistos na Figura 2.

Em cada intervalo de medida de $150 \mathrm{~h}$, foram analisados a variação de vazão, da massa, do coeficiente de descarga e o diâmetro dos bocais. A vazão dos bocais foi analisada pela vazão acumulada medida em cada intervalo de leitura facilitando, assim, a visualização do comportamento da vazão e permitindo estimar-se a porcentagem total de variação de vazão em cada intervalo ou entre vários intervalos de leitura. A granulometria dos sólidos, utilizada na mistura, variou de 0,062 a $0,125 \mathrm{~mm}$ de
A. Bocal de latão

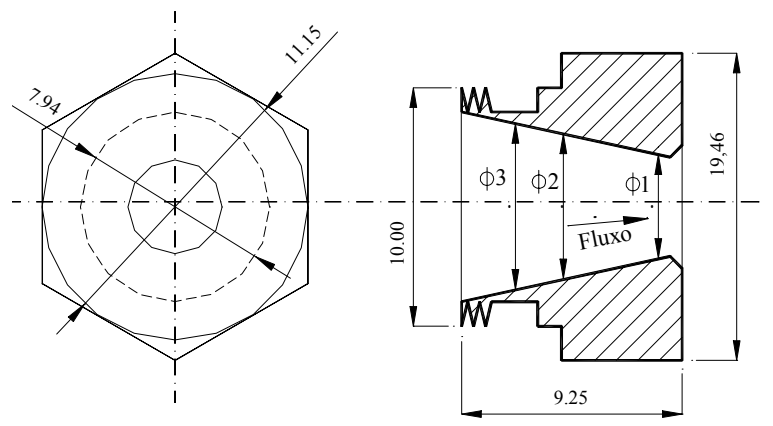

B. Bocal de plástico

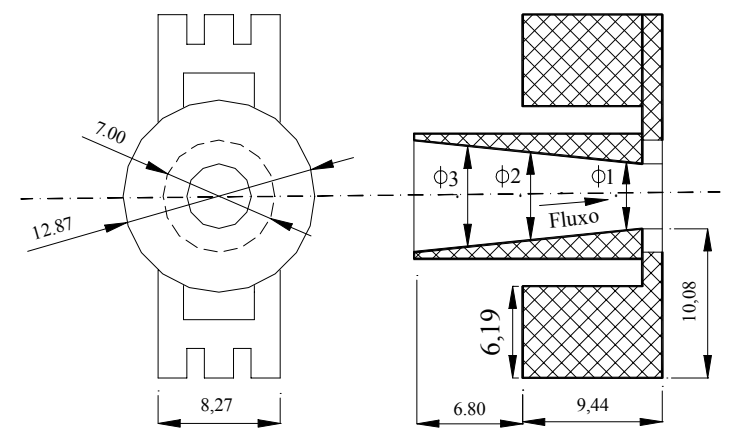

C. Bocal de bronze

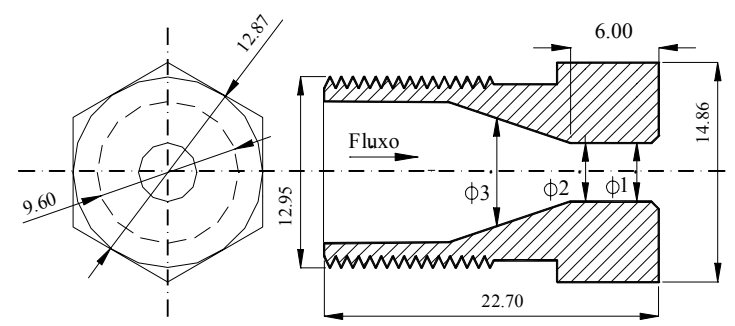

Figura 2. Esquema dos bocais de latão, plástico e bronze

diâmetro e foi definida através de dados da concentração média de sólidos, normalmente encontrada nas águas dos rios da região de Campinas, SP, e que são utilizadas na irrigação, como pode ser encontrado em trabalhos desenvolvidos por Coiado (1997) e Figueiredo et al. (1995).

\section{Dimensões dos bocais}

As medidas do diâmetro foram feitas sempre em três posições no bocal, ou seja, a 1,00 $\mathrm{mm}\left(\varnothing_{1}\right)$, a 5,00 mm $\left(\varnothing_{2}\right)$ e a $7,00 \mathrm{~mm}\left(\varnothing_{3}\right)$, no bocal de latão (Figura 2A) a 1,00 mm (Ø $)$, a $7,00 \mathrm{~mm}\left(\varnothing_{2}\right)$ e a $11,00 \mathrm{~mm}\left(\varnothing_{3}\right)$ no bocal de plástico (Figura $2 \mathrm{~B}$ ) e a $1,50 \mathrm{~mm}\left(\varnothing_{1}\right)$, a $5,00 \mathrm{~mm}\left(\varnothing_{2}\right)$ e a $11,00 \mathrm{~mm}\left(\varnothing_{3}\right)$, no bocal de bronze (Figura $2 \mathrm{C}$ ) tomando-se, sempre, como referência, a face de saída do bocal.

Devido à dificuldade para medição direta do diâmetro do bocal, através de equipamentos convencionais, optou-se pela medição de forma indireta, através da confecção de moldes, sendo que os mesmos foram feitos com resina Araldite ${ }^{(\mathrm{TM})}$ especial, própria para confecção de moldes. Para isto, os bocais foram retirados do aspersor, untados com desmoldante, vedando-se a saída para reter a resina e, em seguida, o bocal foi preenchido com a resina, sendo retirado o molde para realização das medições após $8 \mathrm{~h}$. 
A medição dos moldes dos bocais dos aspersores foi feita com o auxílio de uma máquina de medição por coordenadas de contato mecânico, com precisão de $0,0001 \mathrm{~mm}$. Os bocais de latão, plástico e bronze testados, e seus respectivos moldes, podem ser vistos na Figura 3.
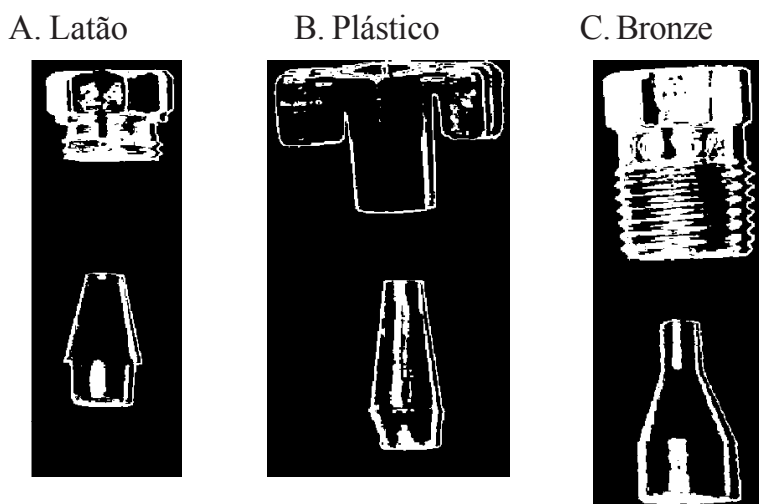

Figura 3. Vista parcial dos bocais de latão, plástico e bronze e seus respectivos moldes

\section{Perda de massa e características hidráulicas}

Para avaliação da perda de massa pesaram-se os bocais em uma balança analítica eletrônica, com precisão de $0,0001 \mathrm{~g}$, a cada intervalo de medida.

O coeficiente de descarga (Cd), foi calculado pela relação entre a vazão teórica determinada pela equação dos orifícios e a vazão estimada experimentalmente, utilizando-se os valores de diâmetro de saída em todos os bocais testados como referência.

\section{RESULTADOS E DISCUSSÃO}

\section{Desempenho do módulo hidráulico}

Durante o desenvolvimento do trabalho alguns inconvenientes foram verificados, um dos quais a coleta de amostras de água para determinação da vazão. Devido ao pequeno espaço existente entre as chapas de suporte dos funis com suas respectivas cúpulas e o reservatório, limitou-se o tamanho do recipiente a ser utilizado para tomada das amostras e, conseqüentemente, o tempo de coleta.

Embora o sistema hidráulico tenha apresentado desempenho satisfatório, durante o período de ensaio, é conveniente utilizar-se um reservatório com maior volume, permitindo que o tempo em que a mistura sólido-líquida recircule totalmente pelo circuito hidráulico seja aumentado possibilitando, também, o aumento do tempo de tomada da vazão, sem baixar o nível do reservatório a ponto de comprometer o funcionamento do sistema.

Constatou-se aquecimento da mistura sólido-líquida, sendo indispensável a instalação de um sistema de arrefecimento sempre que o sistema hidráulico for do tipo circuito fechado; caso contrário, certamente haverá elevação da temperatura da água a níveis prejudiciais ao desenvolvimento dos ensaios.

Foram utilizados os mesmos exemplares de reguladores de pressão durante todo o período de ensaio, não se detectando danos em seus componentes, que pudessem comprometer o seu desempenho e precisão de ajuste de pressão.
As motobombas, tanto as utilizadas como misturadoras ou para bombear a mistura para os aspersores nas duas concentrações de sólido testadas, não sofreram desgaste no rotor, que comprometesse o seu rendimento. Este fato se deve à fina granulometria dos sólidos utilizados, porém a motobomba principal utilizada no ensaio com a concentração $\mathrm{C}_{2}$ apresentou desgaste acentuado no selo mecânico, provocando vazamentos e necessitando a sua substituição após 1300 h de ensaio, aproximadamente.

Considerando-se que a concentração média de sólidos desejada na mistura era de $140 \mathrm{mg} \mathrm{L}^{-1}\left(\mathrm{C}_{1}\right)$ e $230 \mathrm{mg} \mathrm{L}^{-1}\left(\mathrm{C}_{2}\right)$ observou-se que a média de todas as leituras levantadas a cada $150 \mathrm{~h}$, esteve próximo a este valor, com média de $142 \mathrm{mg} \mathrm{L}^{-1} \mathrm{e}$ $226 \mathrm{mg} \mathrm{L}^{-1}$, respectivamente. Os valores que mais se distanciaram da média desejada foram de 153 e $215 \mathrm{mg} \mathrm{L}^{-1}$ para as concentrações $\mathrm{C}_{1}$ e $\mathrm{C}_{2}$ respectivamente dentro, portanto, do limite tolerável de $10 \%$.

Os três modelos de aspersores utilizados apresentaram comportamento distinto no que se refere ao seu funcionamento e ao desgaste dos componentes durante o período de ensaio. Os aspersores que apresentaram melhores condições de funcionamento ao longo do ensaio foram os confeccionados em bronze, seguidos pelos de plástico, não sendo necessária a troca de nenhum componente durante o ensaio; já o aspersor de latão apresentou alguns problemas durante o ensaio, constatando-se desgaste, principalmente nas arruelas de vedação e no mancal, provocando desequilíbrio no seu funcionamento, vazamento de água pelo corpo do aspersor e, em algumas situações mais críticas, o travamento do aspersor, necessitando de sua substituição periódica, porém, se manteve sempre o mesmo bocal, até o final do ensaio. $\mathrm{O}$ aspersor de latão utilizado inicialmente para ambas as concentrações, possuía conexão tipo "fêmea", recomendando-se sua substituição a cada $150 \mathrm{~h}$ de ensaio, aproximadamente. Com a substituição para rosca "macho", a $1050 \mathrm{~h}$ de ensaio, diminuiuse sensivelmente o desgaste que vinha ocorrendo das arruelas de vedação e do mancal, alongando a vida útil.

\section{Avaliação do desgaste e características hidráulicas}

Os valores de vazão obtidos a cada intervalo de leitura para as concentrações de sólido $\mathrm{C}_{1}$ e $\mathrm{C}_{2}$ podem ser vistos na Tabela 1 .

Observou-se que a variação de vazão, obtida para um mesmo tipo de material de bocal, não mostrou diferença em função das concentrações de sólido $\mathrm{C}_{1}$ e $\mathrm{C}_{2}$ a 2100 h de ensaio, porém a concentração de sólido teve maior influência sobre o bocal de latão, seguido pelo de plástico e bronze. $\mathrm{O}$ aumento de vazão verificado nos bocais de latão, plástico e bronze, durante todo o ensaio, foi de $2,97,1,98$ e $0,96 \%$, respectivamente, iguais para ambas as concentrações de sólido, para um mesmo material de bocal.

O tempo de ensaio de 2100 h, para as duas concentrações de sólido estudadas, mostrou maior aumento de vazão para o bocal de latão, porém não o suficiente para justificar a sua substituição, uma vez que tanto os fabricantes de bocais e aspersores como as normas ASAE S471 (ASAE, 1993) e ASTM I641-85 (ASTM, 1991), recomendam substituir somente após atingidos $10 \%$ de aumento de vazão. Embora a vazão tenha sido menor que aquela prevista em norma, para que a 
Tabela 1. Vazão experimental para os bocais de latão, plástico e bronze para as concentrações de sólido $\mathrm{C}_{1}$ e $\mathrm{C}_{2}$ em função do tempo de ensaio

\begin{tabular}{|c|c|c|c|c|c|c|}
\hline \multirow{3}{*}{ Horas } & \multicolumn{6}{|c|}{ Vazão $\left(\mathrm{m}^{3} \mathrm{~h}^{-1}\right)$} \\
\hline & \multicolumn{2}{|c|}{ Latão } & \multicolumn{2}{|c|}{ Plástico } & \multicolumn{2}{|c|}{ Bronze } \\
\hline & $\mathrm{C}_{1}$ & $\mathrm{C}_{2}$ & $\mathrm{C}_{1}$ & $\mathrm{C}_{2}$ & $\mathrm{C}_{1}$ & $\mathrm{C}_{2}$ \\
\hline 0 & 1,01 & 1,01 & 1,01 & 1,01 & 1,04 & 1,05 \\
\hline 150 & 1,02 & 1,02 & 1,01 & 1,01 & 1,04 & 1,05 \\
\hline 300 & 1,02 & 1,02 & 1,02 & 1,01 & 1,05 & 1,05 \\
\hline 450 & 1,02 & 1,02 & 1,02 & 1,02 & 1,05 & 1,05 \\
\hline 600 & 1,03 & 1,03 & 1,02 & 1,02 & 1,05 & 1,05 \\
\hline 750 & 1,03 & 1,03 & 1,02 & 1,02 & 1,05 & 1,05 \\
\hline 900 & 1,03 & 1,03 & 1,02 & 1,02 & 1,05 & 1,05 \\
\hline 1050 & 1,03 & 1,03 & 1,03 & 1,02 & 1,05 & 1,05 \\
\hline 1200 & 1,03 & 1,04 & 1,03 & 1,02 & 1,05 & 1,05 \\
\hline 1350 & 1,03 & 1,04 & 1,03 & 1,03 & 1,05 & 1,05 \\
\hline 1500 & 1,04 & 1,04 & 1,03 & 1,03 & 1,05 & 1,05 \\
\hline 1650 & 1,04 & 1,04 & 1,03 & 1,03 & 1,05 & 1,05 \\
\hline 1800 & 1,04 & 1,04 & 1,03 & 1,03 & 1,05 & 1,05 \\
\hline 1950 & 1,04 & 1,04 & 1,03 & 1,03 & 1,05 & 1,06 \\
\hline 2100 & 1,04 & 1,04 & 1,03 & 1,03 & 1,05 & 1,06 \\
\hline$\Delta$ total $(\%)$ & 2,97 & 2,97 & 1,98 & 1,98 & 0,96 & 0,96 \\
\hline
\end{tabular}

substituição dos bocais fosse necessário, problemas em outros componentes do aspersor ocorreram, sendo oportuno sua substituição. Especificamente, neste trabalho, tal fato ocorreu em especial com o aspersor de latão. Na prática, muitos agricultores preferem substituir todo o aspersor e não apenas as peças danificadas, o que resulta em maiores custos na maioria dos casos, embora em alguns os aspersores simplesmente não são substituídos, resultando em desperdício de água, em maior consumo de energia e, conseqüentemente, danos para a cultura e para o solo, decorrentes da má distribuição de água.

Os valores de $\mathrm{Cd}$ encontrados nos ensaios preliminares mostram valores de 0,93 para o bocal de latão e plástico e de 0,97 para o bocal de bronze. Por outro lado, durante o ensaio o bocal de latão mostrou valor médio de $\mathrm{Cd}$ de 0,92 para a concentração $C_{1}$ e de 0,93 para a concentração $C_{2}$. Para os bocais de plástico, a média foi de 0,93 para a concentração de $\mathrm{C}_{1}$ e de 0,92 para a concentração $\mathrm{C}_{2}$. Para os bocais de bronze, tanto para $\mathrm{C}_{1}$ como para $\mathrm{C}_{2}$, o $\mathrm{Cd}$ não mostrou alterações, permanecendo sempre em 0,97 , indicando que, embora tenha ocorrido pequena alteração no diâmetro dos bocais, principalmente nos de bronze, não se encontrou alteração acentuada nos valores de $\mathrm{Cd}$ dos bocais novos em relação aos testados, mesmo após as $2100 \mathrm{~h}$ de ensaio.

\section{Variação de massa e dimensão dos bocais}

Os bocais de latão e bronze apresentaram decréscimo constante de massa ao longo do ensaio, ao passo que o bocal de plástico apresentou variações positivas e negativas, podendo ser causados por partículas aderidas ao bocal e que não puderam ser retiradas totalmente, por estarem em locais de difícil remoção ou pela absorção de água não retirada totalmente pelo processo de secagem a que foram submetidos.

Os resultados obtidos de variação dos diâmetros $\varnothing_{1}, \varnothing_{2}$ e $\varnothing_{3}$ a 0 e a $2100 \mathrm{~h}$ de ensaio, para as concentrações $C_{1}$ e $C_{2}$ e também a variação em porcentagem para cada concentração a 2100 h em relação ao início do ensaio ( 0 h ) estão apresentados na Tabela 2 .

Tabela 2. Valores dos diâmetros $\varnothing_{1}, \varnothing_{2}$ e $\varnothing_{3}$ a 0 e 2100 h de ensaio e a variação em porcentagem para as concentrações $\mathrm{C}_{1}$ e $\mathrm{C}_{2}$ no final do ensaio $(2100 \mathrm{~h})$ em relação ao início do ensaio $(0 \mathrm{~h})$

\begin{tabular}{|c|c|c|c|c|c|c|}
\hline \multirow{2}{*}{ Diâmetro } & \multicolumn{2}{|c|}{$0 \mathrm{~h}$} & \multicolumn{2}{|c|}{$2100 \mathrm{~h}$} & \multicolumn{2}{|c|}{$\Delta \varnothing(\%)$} \\
\hline & $\mathrm{C}_{1}$ & $\mathrm{C}_{2}$ & $\mathrm{C}_{1}$ & $\mathrm{C}_{2}$ & $\mathrm{C}_{1}$ & $\mathrm{C}_{2}$ \\
\hline & \multicolumn{6}{|c|}{ Latão } \\
\hline$\varnothing_{1}$ & 3,999 & 3,967 & 4,079 & 4,074 & 2,00 & 2,70 \\
\hline$\varnothing_{2}$ & 5,777 & 5,735 & 5,816 & 5,806 & 0,68 & 1,24 \\
\hline$\varnothing_{3}$ & 6,571 & 6,536 & 6,612 & 6,607 & 0,62 & 1,07 \\
\hline & \multicolumn{6}{|c|}{ Plástico } \\
\hline$\varnothing_{1}$ & 3,987 & 4,000 & 4,032 & 4,062 & 1,13 & 1,55 \\
\hline$\varnothing_{2}$ & 5,442 & 5,366 & 5,483 & 5,408 & 0,75 & 0,78 \\
\hline$\varnothing_{3}$ & 6,367 & 6,287 & 6,407 & 6,306 & 0,27 & $-1,58$ \\
\hline & \multicolumn{6}{|c|}{ Bronze } \\
\hline$\emptyset_{1}$ & 3,957 & 3,957 & 3,976 & 3,988 & 0,48 & 0,78 \\
\hline$\varnothing_{2}$ & 3,952 & 3,971 & 3,964 & 3,989 & 0,30 & 0,78 \\
\hline$\varnothing_{3}$ & 7,057 & 6,971 & 7,158 & 7,110 & 1,13 & 1,99 \\
\hline
\end{tabular}

Observa-se que a variação do diâmetro $\varnothing_{1}$ no bocal de latão no final do ensaio para a concentração $\mathrm{C}_{2}$, foi de 2,70 , ou seja, $0,70 \%$ superior a $C_{1}$. Para os diâmetros $\varnothing_{2}$ e $\varnothing_{3}$ a variação do diâmetro para a concentração $\mathrm{C}_{2}$ no final do ensaio foi de 1,24 e $1,09 \%$, respectivamente. Para a $\mathrm{C}_{1}$, o decréscimo do diâmetro foi menor, sendo de 0,68 e $0,62 \%$ para os diâmetros $\varnothing_{2}$ e $\varnothing_{3}$ respectivamente, concordando com Nanduri et al. (2002) que verificaram que, alterando o diâmetro como a concentração das partículas sólidas, o processo de desgaste também é alterado.

Para o bocal de plástico, o decréscimo do diâmetro $\varnothing_{1}$ no final do ensaio foi de $1,55 \%$ para a concentração $C_{2}$, enquanto para $\mathrm{C}_{1}$ foi de $1,13 \%$, mostrando comportamento semelhante ao bocal de latão, ao passo que para $\varnothing_{2}$, os valores de decréscimo foram praticamente iguais para as duas concentrações de sólidos; já para o diâmetro $\varnothing_{3}$, não se encontrou um valor consistente de variação de diâmetro, sendo a causa mais provável a não adaptabilidade deste tipo de resina usada para a confecção de moldes em bocais de plástico, formando falha em alguns pontos localizados do molde; o mesmo, porém, não ocorreu com os bocais de metal. Este fato não foi verificado em trabalho realizado por Nanduri et al. (2002), usando moldes para medir o desgaste interno de bocais, devido, talvez, ao fato de que os moldes foram confeccionados com material de silicone.

Para o bocal de bronze, o decréscimo dos diâmetros $\varnothing_{1}$ e $\varnothing_{2}$ foi menor que nos bocais de latão e plástico, em ambas as concentrações de sólidos utilizadas, sendo de no máximo de $0,78 \%$ para a $\mathrm{C}_{2}$. Para o diâmetro $\varnothing_{3}$, encontraram-se maiores valores comparados aos diâmetros $\varnothing_{1}$ e $\varnothing_{2}$ para as duas concentrações de sólidos. A diferença de desgaste decorre do fato de que este bocal possui um ângulo de $37^{\circ} 70^{\prime}$ e depois converge para ângulo de $0^{\circ}$, ou seja, o decréscimo de desgaste é maior conforme se aumenta o ângulo interno do boca (Truscott, 1972; Karmeli et al., 1982; Boman \& Parsons, 1993; Li \& Kawan, 1998 e Nanduri et. al., 2002). 
A medição dos diâmetros dos bocais, através da confecção de moldes, mostrou-se eficiente e com precisão adequada aos objetivos do trabalho, com melhores resultados para os bocais de metal; entretanto, recomendam-se estudos mais detalhados para se encontrar a forma e o material adequado para confeccionar moldes em bocais de plástico.

\section{CONCLUSÕES}

1. O módulo hidráulico e a metodologia de ensaio são capazes de simular o desgaste de bocais de aspersores para as duas diferentes concentrações de sólidos utilizadas, embora se tenha verificado aquecimento da mistura sólido-líquida, necessitando-se da instalação de um sistema eficiente de arrefecimento em trabalhos futuros.

2. A concentração média de sólidos monitorada durante o ensaio permaneceu dentro dos limites estipulados, demonstrando a boa eficiência do sistema de misturador de sólidos.

3. A metodologia utilizada para a medição dos diâmetros dos bocais, através da confecção de moldes, mostrou-se eficiente e com precisão adequada aos objetivos do trabalho, indicando resultados menos consistentes para o bocal de plástico.

\section{AGRADECIMENTOS}

À FAPESP - Fundação de Amparo à Pesquisa do Estado de São Paulo, pelo auxílio concedido (Processo N. ${ }^{\circ}$ 97/03223-6).

\section{LITERATURA CITADA}

ASAE - American Society for Agricultural Engineers, ASAE Standard, ASAE S471. Procedure for measuring sprayer nozzles wear rate. $1993,5 \mathrm{p}$.
ASTM - American Society for Testing Materials. Standard Methods for testing agricultural hydraulic spray nozzles. Philadelphia, 1985, 5p. ASTM, E 641-85, 1991

Boman, B.J.; Parsons, M.L. Changes in microsprinkler discharges resulting from long-term use. Applied Engineering in Agriculture. Florida, v.9, n.3, p.281-284, 1993.

Coiado, E.M. Distribuição de velocidade e concentrações de sedimentos para o estudo da descarga sólida transportada em suspensão pelo Rio Atibaia/SP. Campinas: Faculdade de Engenharia Civil, Universidade Estadual de Campinas. Campinas, 1997. Relatório de bolsa de pesquisa-CNPq

Figueiredo, A.G.; Júnior, M.S.U.; Nogueira, A.A.S.; Neto, F.L. A dinâmica da produção e transporte de sedimentos em suspensão na bacia do rio Aguapeí. Departamento de Engenharia Hidráulica e Sanitária (BTPHD), n. 17, 1995, 29p. Boletim Técnico da Escola Politécnica da USP

ISO - International Standard for Standardization - ISO 7749-1. Agricultural irrigation equipment - Rotating sprinklers. Part. 1: Design and operational requirements. 2. ed., Geneva, 1995. p.1-12.

Karmeli, D; Peri, G; Todes, M. A model for sprinkler nozzle replacement. Transaction of the ASAE, St. Joseph, v.25, n.5, p.1284-1289, 1982.

Li, J.; Kawan, O,H. Sprinkler performance as affected by nozzle inner contraction angle. Irrigation Science, v.18, p.63-66, 1998.

Nanduri, M.; Taggart, D.G.; Kim, T. The effects of system and geometric parameters on abrasive water jet nozzle wear. International Journal of Machine Tools \& Manufacture. Elsevier Science, v.42, p.615-623, 2002.

Truscott, G.E. A literature survey on abrasive wear in hydraulic machinery. Journal Wear, v.20, p.29-50, 1972. 